\title{
Teaching Turkish as a Foreign Language and Problems Encountered
}

\section{Z. Canan CANDAŞ KARABABA*}

\begin{abstract}
Currently, Turkish courses as a foreign language are provided by the schools, the language schools subject to universities, or the language schools subject to private institutions through different levels of course curricula. The study covers the problems encountered in the teaching of Turkish as a foreign language and the considerations of the teaching staff of this field. The study is a qualitative study. The data analysis is carried out via semi-structured interviews. The participants of the study comprise the teaching staff that is experienced in the teaching of Turkish as a foreign language for a period of 10 years at least. The voluntary teaching staff is employed both in two schools subject to universities and a private school subject to the Ministry of Education. The problems encountered in the teaching of Turkish as a foreign language are identified under the light of the teaching staff's voluntary considerations. On account of the occasion that the teaching of Turkish as a foreign language does not have a long history, there are few investigations regarding the education programs and the students' needs. Therefore, it is necessary that multi-aspect identifications in regard to the teaching of Turkish as a foreign language and its problems in addition to the relevant studies be carried out. Ultimately, this study dwells on the problems encountered in the teaching of Turkish as a foreign language in terms of education programs, education environments and the students. Following the identification of the problems, they are expounded and some resolutions as to these problems are put forward.
\end{abstract}

Key Words: Teaching Turkish, foreign language learning, curriculum, multi-cultural classes, language and culture.

* Assist. Prof. Dr. Ankara University, Faculty of Educational Sciences 


\section{SUMMARY}

Teaching Turkish can be discussed under two main titles: The teaching of Turkish as a mother tongue and a foreign language. The teaching of Turkish as a foreign language has been discussed in this study and the problems encountered in the teaching of Turkish as a foreign language have been evaluated under three titles:

1. The Curriculum Problem,

2. The Teaching Environment Problem,

3. The Problems Encountered by Students.

The first and most important problem in the teaching of Turkish to foreigners is the inadequacy of the curricula and the studies, which may act as sources for the development of these curricula. For the purpose of solving this problem, there is need for a curriculum, which is suitable for the needs of this target group, and books, which are prepared in conformity with this curriculum and according to the level of the students while containing sufficient pictures and literary texts. Another problem is that the age and the level of the students are not considered when the curricula are being prepared.

The teaching of Turkish as a foreign language being the case, in parallel with the curricula various problems are encountered in the creation of the teaching environments suitable for age and level or in relation to the characteristic of the teaching environment. By considering whether it is in Turkey or abroad, creating teaching environments with a suitable equipment for the age and the level of the student may be a solution for the teaching environment problem. In addition, there are "multi language, multicultural" learning environments involving students from different cultures which share the same environment. Establishing communication between the students and arranging inner and outer class activities to develop this communication in such environments needs the knowledge and the effort of the teaching staff. Therefore, the teachers need to have knowledge concerning various teaching environments and the needs of students in these environments.

When observed from the perspective of the students, the various learning problems encountered in the learning of any foreign language are also effective for the learning of Turkish. Various problems are encountered in the learning of the components of a language or the development of skills for the use of a language. These problems have been discussed in the third and final sections of the study under the titles of problems pertaining to pronunciation, morphology, syntax, semantics and suggestions, which may help providing the solutions for these problems presented. 


\section{Yabancı Dil Olarak Türkçenin Öğretimi Ve Karşılaşılan Sorunlar}

\section{Z. Canan CANDAŞ KARABABA*}

ÖZ. Günümüzde Türkçe yabancı dil olarak üniversitelere bağlı dil kurslarında okullarda veya özel kuruluşlara bağlı dil okullarında, aşamalı kur sistemiyle, öğretilmektedir. Araştırmamızda, bu alanda çalışan öğretim elamanlarının da görüşleri alınarak yabacı dil olarak Türkçenin öğretiminde karşılaşılan sorunlar ele alınmıştır. Araştırma, örnek olay incelemesi olarak yapılmıştır. Verilerin toplanmasında nitel araştırma tekniklerinden yarı yapılandırılmış görüşme tekniği kullanılmıştır. Araştırmanın katılımcıları, yabancılara Türkçe öğreten en az on yıl deneyimli öğretim elemanlarıdır. Öğretim elemanları üniversitelere bağlı iki ve Milli Eğitime bağlı özel bir okulda çalışmaktadırlar ve araştırmaya gönüllü olarak katkıda bulunmuşlardır. Çalışmaya katılan öğretim elamanlarının görüşlerinden hareketle günümüzde yabancı dil olarak Türkçenin öğretiminde karşılaşılan güçlükler tanımlanmıştır. Türkçenin yabancı dil olarak öğretiminin, uzun bir geçmişe sahip olmaması nedeniyle, öğretim programları, öğrenci gereksinimlerine ilişkin araştırmalar çok değildir. Bu nedenle yabancilara Türkçe öğretimine ve öğretilirken karşılaşılan sorunlara ilişkin çok yönlü tanımlamalara ve bunlara koşut araştırmalara gereksinim vardır. Bu çalışmada, yabancılara Türkçe öğretiminde karşılaşılan sorunlar, öğretim programları, öğretim ortamları ve öğrenenler açısından ele alınmıştır. Sorunlar tanımlandıktan sonra yorumlanarak değerlendirilmiş ve çözüm önerilerinde bulunulmuştur.

Anahtar sözcükler: Türkçe öğretimi, yabancı dil öğrenimi, eğitim programı, çok kültürlü sınıflar, dil ve kültür.

\footnotetext{
*Yrd. Doç. Dr., Ankara Üniversitesi, Eğitim Bilimleri Fakültesi.
} 


\section{GíRIȘ}

Türkçe öğretimi; Türkçenin anadili ve yabancı dil olarak öğretimi olmak üzere iki ana başlık altında ele alınabilir. Günümüzde Türkçenin anadili olarak öğretiminde çeşitli sorunlar yaşanmaktadır. Bu sorunlarla ilgili tartışmalar, dilin doğru kullanımını ve gelişimini etkileyeceğinden çok önemlidir. Anadili öğretimindeki sorunlar, çok konuşulup tartış1lırken Türkçenin yabancı dil olarak öğretimine ilişkin sorunların tartışılması ikincil veya daha az önemli bir sorun gibi görülebilir. Ancak bir dilin gelişmiş olması, zengin olması; sadece anadili olarak etkin bir biçimde öğretiliyor olmasına veya o dildeki sözcük sayısına, o dille üretilmiş yapıtlara, o dilin düzgün ve kurallarına uygun biçimde toplumda kullanılıyor olmasına bağlı değildir.

Bugün dünyada yaygın biçimde benimsenmiş; sanatta, teknolojide, uluslararası iletişimde en çok kullanılan diller, yabancı dil olarak öğretimi gelişmiş dillerdir. Bir dilin yabancı dil olarak öğretilmesi; o dilin sadece kendi sınırları içinde kalmayıp diğer uluslar ve kültürlerle iletişime girmesi, tanınması ve sağlıklı biçimde öğretilebilmesi için o dilin; daha çok gelişmesi, o dil üzerine ve öğretimine ilişkin daha çok çalışma yapılması anlamına da gelir. Türkçenin yabancı dil olarak öğretimi yaygınlaştıkça ögretim materyalleri ve öğretim ortamları çeşitlenmekte ve gelişmektedir. $\mathrm{Bu}$ gelişime ayak uydurma ve çağdaş öğretim yöntemlerini Türkçenin yabancı dil olarak öğretiminde uygulama çabaları sürerken çeşitli sorunlarla karşıllaşılmaktadır.

$\mathrm{Bu}$ çalışmada, yabancılara Türkçe öğretiminde karşılaşılan sorunlar; öğretim programları, öğretim ortamları ve öğrenci açısından ele alınmıştır.

"Öğretim Programları" başlıklı 1. bölümde yabancılara Türkçe öğretimindeki program sorununa, "Öğretim Ortamları" başlıklı 2. bölümde ise ögrretim ortamları ve bu ortamlarda kullanılan araç-gereçlerle ilgili sorunlara yer verilmiştir. 3. bölümde Türkçenin yabanc1 dil olarak öğreniminde özellikle yetişkinlerin sıklıkla karşılaştıkları sorunlara yer verilmiş̧ir.

\section{YÖNTEM}

Araştırma nitel bir araştırma yöntemi olan örnek olay incelemesi olarak yapılmıştır. Verilerin toplanmasında nitel araştırma tekniklerinden yarı yapılandırılmış görüşme tekniği kullanılmıştır. Yarı yapılandırılmış görüşmede araştırmacı, görüşme sorularını önceden hazırlar, kişilere sınırlı(kısmi) bir esneklik sağlayarak soruları yeniden düzenleyebilir 
(Creswell, 1998; Yıldırım ve Şimşek, 2006; Kılınç, 2007; Karasar, 2009). Görüşme sonucunda elde edilen verilerin çözümlenmesinde nitel veri analizi tekniklerinden betimsel analiz tekniği kullanılmıştır. Betimsel analiz yapılırken elde edilen veriler daha önceden belirlenen temalara göre özetlenip yorumlanmıştır. Yarı yapılandırılmış görüşme soruları ise 3 alt başlıktan oluşmaktadır:

i) Yabancılara Türkçe öğretiminde öğretim programlarına ilişkin sorular.

ii) Yabancılara Türkçe öğretiminde öğretim ortamlarına ilişkin sorular.

iii) Yabancılara Türkçe öğretiminde öğrencilerin karşılaştıkları sorunlara ilişkin sorular.

Araştırma grubu, yabancılara Türkçe öğretimi veren üniversitelere bağlı iki ve MEB' e bağlı özel bir dil okulunda öğretim veren öğretim elemanlarından seçilmiştir. Yabancılara Türkçe öğretimi veren 48 öğretim elemanından çalışmaya gönüllü olarak katılmak isteyip, en az on yıl deneyimi olanlar dahil edilmiş̧ir. Yarı-yapılandırılmış görüşmeler, 18 öğretim elemanı ile tamamlanmıştır.

Görüşme formunun geçerliğini sağlamak için görüşme formu iki alan uzmanına ve bir ölçme değerlendirme alan uzmanına inceletilerek forma son şekli verilmiştir.

Görüşmeler kaset çalar ile kayda alınmış, notlar tutulmuş ve bu veriler daha sonra çözümlenmiştir. Çözümleme aşamasında iki bağımsız araştırmacı üç kişiye ait otuz dakikalık kaydı birbirlerinden farklı yer ve zamanda çözümlemişlerdir. Bağımsız araştırmacılar arasında .89 oranında tutarlılık görülmesi üzerine, araştırmacı çözümleme işlemine tek başına devam etmiştir. Araştırmaya katılan öğretim elemanlarının görüş ve düşünceleri çalışma içerisinde yeri geldikçe verilmiştir.

\section{BÖLÜM: ÖĞRETIMM PROGRAMLARI}

Yabancılara Türkçe öğretimi konusunda en önemli sorunlardan biri öğretim programlarının geliştirilmesine kaynaklık edecek Türkçenin dilbilgisini işlevsel açıdan ve her yönüyle betimleyen çalışmaların yeterli olmamasıdır. Yabancı dil olarak Türkçeyi öğretenlerle yapılan görüşmelerde çoğunluk tarafindan bu görüş gündeme getirilmiştir. Katılımcılardan biri tarafından da şu şekilde açıklanmıştır:

Türkçe öğretmeye başladı̆̆ımızda daha çok deneme yanılma yoluyla ders materyalleri oluşturduk. Yaş düzeyine uygun kaynak kitaplar yoktu. 
Öğretmen kendi kişisel çabalarıyla bir şeyler oluşturmaya çalışmıştır. Yabancllara Türkçe ögretimi derslerinde düzeye uygun olarak yeri geldikçe dilbilgisi konularını anlattım ancak zorlandım.

Bir dilin etkin biçimde öğretilebilmesi ve bu öğretime uygun programın geliştirilebilmesi için, öncelikle o dilin yapısal ve anlamsal özelliklerinin her yönüyle basitten karmaşığa giden bir yapıda ve öğrenenlerin düzeylerine göre tanımlanmış olması gerekir. Bilindiği gibi Türkçenin dilbilgisini betimleyen yapıtlar, değerli çalışmalar vardır; ancak bu yapıtlar daha çok Türkçenin anadili olarak öğretimine kaynaklık edebilecek niteliktedir.

Yapılan görüşmelerde katılımcıların, ikisi hariç çoğunluğu Türkçenin yabancı dil olarak öğretimine kaynaklık edebilecek ürünlerin yeterli olmadı ğını belirtmiştir.

Belli bir eğitim programı yoktur çünkü işlenecek konuların içeriği okutulan kitap ve ögretmen kitabinda yer almaktadır.

Katılımcıların da belirttiği gibi Türkçenin yabanc1 dil olarak öğretiminde, öğrenenlerin gereksinimlerine ve düzeylerine uygun öğretim programlarının geliştirilmesi gerekmektedir. Türkçeyi yabancı dil olarak öğrenenler çocuklar ise çocuklara uygun resimler ve yazınsal metinlerle donatılmış kitaplar ve onların yaş düzeyine uygun ders programları düzenlenmelidir. Ne yazık ki günümüzde Türkçeyi yabancı dil olarak öğreten kurumların ders programları incelendiğinde bu tür bir ayrıma gidilmediği gözlenmektedir.

Çocukların ve yetişkinlerin dil öğrenme biçimleri tamamen farklı olduğu gibi anadili ve yabancı dil öğrenme süreçleri de tamamen farklıdır. Çocuklar anadillerini edindikleri gibi yabancı bir ülkede yaşadıklarında ikinci dili de rahatlıkla öğrenebilir, edinebilirler. Burada "edinebilirler" sözünü kullanmak daha doğru olacaktır; çünkü çocuklar anadillerini duyarak ve yineleyerek kullanmaya başlar. Başka bir söyleyişle dilin kurallarını öğrenmeden önce duydukları sesleri taklit ederek, sonra daha karmaşık yapıları ve kullanımları yineleyerek doğal yolla dili edinirler. Yabancı dil öğreniminde ise bu süreç tersine işler. Öğrenen açısından bakıldığında, dil öğrenenlerin gereksinimlerine koşut olarak çeşitli öğretim programlarının uygulanması gerekliliği doğarken; öğretim elemanı açısından da bu çeşitliliğe uygun donanımda olma gerekliliği doğmaktadır.

Bugün üniversitelerimizde lisans düzeyinde Türk Dili ve Edebiyat1, Dilbilim ve Türkçe Eğitimi Bölümleri (Türkçe Öğretmenliği Programları) bulunmaktadır. $\mathrm{Bu}$ bölümler, yabancılara Türkçe öğretimi görevini üstlenmeye uygun ya da en yakın alanlar gibi görünse de söz konusu 
bölümlerin lisans ve varsa lisansüstü programları incelendiğinde; program içeriklerinin, yabancılara Türkçe öğretiminin gerekliliklerini yerine getirebilecek nitelikte ve yabancılara Türkçe öğretmek gibi özel bir alana öğretmen yetiştirmek için yeterli olmadığı görülmektedir.

\section{BÖLÜM: ÖĞRETIM ORTAMLARI}

Günümüzde dil okullarında, özel veya resmi kuruluşlara bağlı dil kurslarında, Türk Silahlı Kuvvetleri bünyesinde (yurtdışından gelen öğrencileri eğitmek amacıyla), yurtdışındaki Türkoloji merkezlerinde veya bölümlerinde, yurtiçinde bazı üniversitelere bağlı dil okulları, uzaktan eğitim merkezlerinde ve üniversitelerin yabancı diller bölümlerine bağlı birimler veya araştırma ve uygulama merkezlerinde Türkçe öğretimi yürütülmektedir. Bu merkezlerde, yabancılara Türkçe öğretiminin çağdaş yöntemlerle ve ders kitaplarıyla gerçekleştirilmesi hedeflenmektedir.

Yabancılara Türkçe dersleri aşamalı kur sistemiyle verilmektedir. Türkçe kursları, temel olarak; başlangıç $(\mathrm{A} 1, \mathrm{~A} 2)$, orta, yüksek ve ileri düzeyler için belirlenmiş sınıflarda ve söz konusu düzeylere uygun ders kitaplarıyla Türkçe kurslarında yürütülmektedir. Ayrıca günümüzde yabancılara Türkçe dersleri uzaktan eğitim programları yardımıyla da gerçekleştirilmektedir.

Türkçe kurslarına devam eden öğrenciler genellikle yetişkinlerdir. Bu yetişkinler arasında Türkiye'ye çalışmak veya okumak için gelenlerin, Türklerle evli olanların yanı sıra gazeteci, yazar olarak veya diplomatik görevlerle gelenler ve aileleri de bulunmaktadır.

$\mathrm{Bu}$ amaçlarla Türkiye'ye gelenler; Türkçeyi, Türkleri, Türkiye'yi tanımak ve Türklerle daha iyi iletişim kurmak için öğrenirler. Çoğunluğunu yetişkinlerin oluşturduğu bu hedef kitlenin gereksinimleri iyi belirlenmediğinde; yaşa ve düzeye uygun öğretim ortamları yaratılmadığında çeşitli sorunlarla karşılaşılmaktadır. Öğretim elemanlarıyla yaptığımız görüşmelerde "çok dilli çok kültürlü” öğrenme ortamlarının özelliklerine ilişkin bir ders aldınız mı? Sorusunun yanıtı iki katılımcı hariç hayırdır.

Eğitim programı (lisans) içinde böyle bir ders olmadı̆̆ için almadım ve şimdi de olduğunu düşünmüyorum.

Türkiye'de yabancı dil olarak Türkçe öğrenenler, çeşitli ülkelerden gelen yabancı öğrencilerdir. Aynı sınıfı paylaşan bu öğrenciler birbirlerine de yabancıdır. Dil öğretimi sınıflarında, etkinliklerin (karşlıklı konuşma, drama çalışmaları, grup çalışması vb.) sağlıklı bir şekilde 
gerçekleştirilebilmesi için öğretim elemanlarının "çok dilli, çok kültürlü” diye tanımlanan bu tür sınıflarda, öğrenciler arasındaki iletişim ortamını yaratabilmesi için özel çaba göstermesi ve bu sınıflarda öğretim ortamlarının sağl1klı biçimde düzenlenmesi için çeşitli iletişim teknikleri konusunda bilgili olması gerekir. $\mathrm{Bu}$ nedenle öğretim elemanının, bu tür öğrenme ortamlarının özelliklerine ilişkin bilgiyi, ögrenimi sırasında almış olması ve bu tür öğrenme ortamlarına hazırlıklı olması gerekir.

Türkçe öğrenenlerin çeşitliliği ile birlikte çeşitli öğrenme ortamları da oluşmaktadır.

Türkçeyi Türkiye'de çok kültürlü sınıflarda öğrenenlerin yanı sıra kendi ülkelerinde aynı kültürden kişilerle birlikte öğrenenler de vardır. Türkçeyi Türkiye'de yabancı dil olarak öğrenenlerin yanı sıra yurtdışında öğrenenler, örneğin yurtdışında Türkçe öğrenen yabancılar ve yurtdışında yaşayan Türk ailelerin orada doğmuş çocuklarının Türkçe öğrenme ortamları da bu çeşitliliği gösteren farklı öğrenme ortamlarına örnek oluşturur. Doğal olarak Türkçeyi yabancı dil olarak Türkiye'de öğrenenlerle yurtdışında öğrenenlerin gereksinimleri farklıdır. Türkçenin yabancı dil olarak öğrenimi ve ikinci dil olarak öğrenimi sırasında öğrenme ortamları farklılaştıkça, öğrenenlerin öğrenme biçimleri ve öğrenme izlenceleri de değişecektir.

Türkçeyi Türkiye'de yabancı dil olarak öğrenenler günlük yaşamlarında da Türkçeyi duyabilir, kullanabilirler. Dille birlikte kültürü de yaşayarak öğrenebilir, edinebilirler. İkinci durumda ise, yani Türkçeyi Türkiye dışında öğrenenler çevre ve kültür, günlük yaşam içinde bulunma gibi dil öğrenimini destekleyen durumlardan yoksundurlar. Böyle bir durumda, sınıf ortamında dil öğrenimi sürecinin görsel, işitsel araçlarla; günlük konuşma dilinden, gazete ve dergilerden alınan metinler, televizyon, radyo programları gibi dilin günlük yaşamda çeşitli ortamlarda kullanılışını yansıtan araç-gereçlerle (materyallerle), desteklenmesi gerekecektir.

\section{BÖLÜM: ÖĞRENCILLERIN KARŞILAŞTIKLARI SORUNLAR}

Öğrenci açısından bakıldığında da yabancı dil öğrenimi kolay bir süreç değildir. Yabancı dil öğrenen; yeni bir ses düzeni, biçim, sözdizimi ve kendi anadilinden farklı bir anlam evreni ve anlatım biçimleriyle karşılaşır ve ister istemez bunları kendi anadiliyle karşılaştırır. Dilbilgisi yapılarını çözümleme yoluna gider, çeşitli sorunlarla karşılaşır. Bu sorunları aşabilmek için bir yöntem geliştirir. Sadece dilbilgisi konusunda değil, sözcük öğrenme, sözcüklerin doğru sesletimi ve metin inceleme, dinleme-anlama, okumaanlama gibi konularda da öğrenme deneyimleri yaşar ve çeşitli sorunlarla karşılaşır. Yapılan görüşmelerde öğretmenler öğrencilerin karşılaştıkları çeşitli sorunları dile getirmiş̧lerdir. $\mathrm{Bu}$ sorunlar aşağıdaki gibi sınıflandırılmıştır. 


\subsection{Türkçenin Sesletimiyle İlgili Sorunlar:}

Yabancı öğrencilerin Türkçe öğrenirken sözcüklerin sesletimiyle ilgili yaşadığ kaynaklanan sorunlardır. Yapılan görüşmelerde öğretim elemanları, dillerin farklı ses yapılarından kaynaklanan öğrenme sorunlarını aşmak için çeşitli alıştırmalar yaptıklarını ancak bunların yeterli olmadığını bazen ileri kurlarda bile sesletimle ilgili sorunlar yaşandığını dile getirmişlerdir.

$\mathrm{Bu}$ farkl1lıklar nedeniyle yabancılar, Türkçeyi öğrenirken sesletimle ve sesleri algılamada, yazmada çeşitli sorunlar yaşar. Örneğin, anadili Arapça olan bir öğrencinin "ö” sesini çıkarabilmesi çok zordur. Çünkü bu ses, kendi dilinde bulunmamaktadır. Anadili Japonca olan bir öğrencinin ise "r" sesi ile "l" sesi arasındaki ayrımı duyumsaması çok zordur. Çünkü Japoncada "l" sesi yoktur. Bu nedenle Japon öğrenciler "l" sesi yerine kendi dillerinde sesletimi bu sese en yakın olan " $r$ " sesini ve yazıda da " $r$ " harfini kullanırlar. $\mathrm{Bu}$ örnekleri çoğaltmak olasıdır. Bu gibi sorunlara sadece Türkçenin yabancı dil olarak öğreniminde değil diğer dillerin öğreniminde de karşılaşıllır. Herhangi bir yabancı dil öğreniminde karşılaştığımız ilk düzen, o dilin söylenişi ve yazılışına ilişkindir.

\subsection{Biçimbilgisi Açısından Yaşanan Sorunlar:}

Yabancıların Türkçe öğrenirken en çok zorlandığı konulardan biri de eklerin kullanımıdır. Özellikle belirtme durumu eki (-1,-i, -u, -ü) ve yönelme durumu eki (-a, -e) kullanmada yabancı öğrenciler zorlanır. Doğaldır ki bu zorlanmada öğrencilerin anadilinin etkisi büyüktür.

Türkçedeki bulunma durum eki (-da, -de) İngilizcedeki "in, on, at" kullanımını içerir. Türkçenin yabancı dil olarak öğretildiği sınıflarda yapılan gözlemler ve araştırmalar sonucunda ad durum eklerinin kullanımında yapılan yanlışların, Türkçe öğretiminde önemli bir yer tuttuğu söylenebilir.

Gramer dizinindeki siralama derslerde zorlanmamiza sebep oluyor. Özellikle ad durum eklerinin öğretim siralamasındaki yeri çok önemlidir.

Ad durum eklerinin öğretimiyle ilgili Özkan (1994: 40) yaptığ1 araştırmada öğrencilerin yazılı anlatım örneklerini taramış ve sonuçları değerlendirmiştir. $\mathrm{Bu}$ araştırmanın sonucu da öğretmen görüşlerini desteklemektedir. $\mathrm{Bu}$ araştırmada yabancı öğrencilerin (A.Ü. TÖMER'de yabancı dil öğrenen karma gruplar) yazılı anlatım örneklerinin taranması sonucunda ad durum eklerinin kullanımıyla ilgili yanlış türleri belirlenmiş ve beş ana başlık altında toplanmıştır. Bu başlıklar: 
1. Ad durum ekinin kullanılmaması, $\% 52.7$

2. Ad durum ekinin gereksiz olarak kullanılmasl, \%21.9

3. Kullanılması gereken ad durum ekinin yerine başka bir ad durum ekinin kullanılmast, \%25.4

4. Ad durum eklerinin ünlü, ünsüz uyumlarına göre yanlış kullanılması.

5. Ad durum eklerinin cümlenin yanlış ögesinde (öznede) kullanılmast. (Son iki grupta yapılan hatalar çok az olduğundan yüzdelik oranlar verilmemiştir.)

Özkan (1994: 40)

\subsection{Tümce Kuruluşu Açısından Yaşanan Sorunlar}

Yukarıda sözü edilen ad durum eklerinin kullanımına ilişkin sorunlar, tümce kuruluşuna ilişkin sorunlara da yol açar. Bilindiği gibi ad durum ekleri, tümcenin öğeleri arasında ilgi kurarak adı eyleme bağlar. Ad durum ekleri doğru kullanılmadığında öğrencilerin düzgün tümce kurmada da güçlük çektikleri gözlenmektedir. Buna ek olarak en çok zorlanılan konulardan biri de tümce ögelerinde uyum, özne-yüklem uyumudur.

Türkçenin yapısal özelliklerinden daha doğrusu yabancı öğrencinin anadilinin yapısal farklılıklarından kaynaklanan bu sorun, sadece Türkçenin yabancı dil olarak öğreniminde değil, bütün dillerin yabanc1 dil olarak öğreniminde yaşanabilecek bir sorundur. Başka bir söyleyişle yabancı dil ögreniminde yaşanan doğal bir durumdur. Ancak burada önemli olan bu sorunların nasıl aşılacağını bilmektir. Öğrenciye dilbilgisi kurallarını öğretmek; öğrencinin, Türkçeyi rahatlıkla yazılı ve sözlü iletişimde kullanabilmesi anlamına gelmemektedir.

Türkçeyi yabancı dil olarak öğrenen bir kişiye yoğunlaştırılmış bir dilbilgisi eğitimi vererek onu Türkçeyi konuşabilen, anlayabilen ve yazabilen biri haline getirmiş olur muyuz? Sorusuna tüm öğretim elemanları "hayır" yanıtını vermiştir.

Öğrenciler açısından önemli bir sorun da dilbilgisi açıklamaları ve alıştırmalarla geçen derslerdir. Sadece Türkçenin yabancı dil olarak öğretilmesinde değil, diğer dillerin ve yaygın olarak öğrenilen Avrupa dillerinin öğretiminde de yaşanmış bir sorundur. Bilindiği gibi İngilizce, Almanca, İspanyolca gibi dillerin yabancı dil olarak öğretimine uzun yıllardır emek veren Avrupa; dilbilgisi-çeviri, kulak dil alışkanlığı, bilişsel yöntem, seçmeci yöntem gibi pek çok dil öğretim yöntemini denedikten sonra tüm bu deneyimlerin sonuçlarını ve dilbilimsel bulguları 
harmanlayarak yabancı dil öğretiminde ELP (European Language Portfolio) Avrupa Dil Gelişim Dosyası kullanımını gündeme getirmiştir.

\subsection{Anlam Bilgisine İlişkin Sorunlar}

Her dilin kendine özgü bir anlatım biçimi, anlam evreni vardır. Atasözleri deyimler, kalıplaşmış sözler bunun en güzel yansıtıcılarıdır. Örneğin, Türkçede 'Afiyet olsun', 'Eline sağlık' gibi yemek ve sofrayla ilgili kalıp sözler çoktur. Bu gibi sözlerin, anlatım biçimlerinin batı dilleriyle karşılaştırıldığında Türkçede daha sıklıkla kullanıldığı gözlemlenir (Karababa, 1993:111) Türkçeyi yabancı dil olarak öğrenenlerin de dikkatini çeken bu durum, Türkçe öğretiminde bir sorun olarak tanımlanamasa da, öğrencinin anadilinde bu gibi sözlere karşılık olmaması veya başka biçimde ifade ediliyor olması Türkçe öğretenlerin bu konuya özen göstermesi ve kültürümüzü yansıtan atasözü, deyim ve kalıp sözlere, Türkçe derslerinde özenle yer verilmesi gerekliliği araştırmaya katkıda bulunan öğretim elemanları tarafindan da dile getirilmiştir.

Pireyi deve yapmak, ateş düştüğ̈̈ yeri yakar, etekleri zil çallyor gibi deyimleri sözcüğü sözcüğüne yabancı dile çevirirsek yabancı bir öğrenciye pek de bir şey ifade etmez. Bu gibi sözlerin anlam yüklerinin ve kullanıldığı yerlerin verilmesi gerekir. Türkçenin varsıllığını ve Türk kültürünü yansıtan bu geleneksel sözleri incelediği çalışmasında; Akerson (1991: 79-88) kalıp sözlerde anlam başlığı altında diğer dillerle karşılaştırmalı olarak atasözleri, deyimler, durumlara özgü kalıp sözler ve argo sözlere yer vermiştir.

Deyimlerin çevirisine ilişkin görüşünü Akerson şu şekilde dile getirmektedir:

Deyimlerin çevirisi bazen atasözlerinden daha güç olur. Bunlar da toplumlara özgüdür, yan anlamlarl o toplumun dilini konuşanlarca bilinir. Bir deyimin karşılı̆̆ öteki dilde deyim olarak bulunabilir ya da bulunmayabilir. Bunlarl çevirirken de içeriği sabit tutmak gerekir, anlatım farklı olabilir, bazen özellikle de farklı olmak zorundadır.

Akerson (1991: 83)

Deyimler ve atasözlerinin öğretiminde de bu yol izlenmelidir. Yabancı bir dil öğretirken olanaklar elverdiğince öğrenilen dilden anadile çeviri yoluna gidilmemelidir. Ancak anlamdan yola çıkarak örneklerle, öğrencinin dil düzeyine uygun açıklamalar ve görsellerden yararlanarak bu gibi sözleri öğretme yoluna gidersek Türkçenin anlatım gücünü yansıtabiliriz.

\footnotetext{
${ }^{1}$ Bu konuda bkz. Little, D. ve R. Perclova. (2000) European Language Portfolio Guide for Teachers and Teacher Trainers.
} 


\section{SONUÇ VE ÖNERILER}

Türkleri, Türkiye'yi, tanımak ve Türklerle daha iyi iletişim kurmak amacıyla yurtiçinde ve dışında Türkçe öğrenmek isteyenlerin sayısı hızla artmaktadır. Bu isteği karşılamak Türkçeyi ve dolayısıyla Türkiye'yi tanıtma olanağını en iyi biçimde değerlendirebilmek için yabancılara Türkçe öğretimi konusu titizlikle ele alınmalıdır. Günümüzde, özellikle son 20 yıldır Türkçenin yabancı dil olarak öğretimi yaygınlaşmış ve başarıyla gerçekleştirilmektedir.

Ancak bu gelişim sürecinde yaşanan, bazı sorunlar vardır. Bu sorunların bazıları tanımlanmış bazıları ise tanımlanmamıș veya üzerinde fazla durulmayan sorunlardır. Aşağıda bu sorunlara değinilmiş ve çözüm olabilecek öneriler sıralanmıştır:

1. Türkçenin yabancı bir dil olarak çağdaş dil öğretim yöntem ve teknikleriyle öğretilebilmesi için Türkçenin dilbilgisini işlevsel açıdan ve her yönüyle betimleyen çalışmaların yeterli olmaması, Türkçenin yabancı dil olarak öğretilmesinde kullanılacak ders kitaplarına kaynaklık edememesi önemli bir eksikliktir. Türkçenin dilbilgisini işlevsel açıdan ve her yönüyle betimleyen çalışmalar, Türkçenin yabancı dil olarak öğretimine kaynaklık etmelidir.

2. Türkçeyi yabancı dil olarak öğrenenlerin; gereksinimlerine, düzeylerine, çeşitliliğine uygun öğretim programları bulunmamaktadır. Türkçeyi Türkiye'de öğrenenlerin yanı sıra yurtdışında öğrenenlerin veya yurtdışında yaşayan Türk çocukların Türkçe öğrenimi için çeşitli ders programları oluşturulmalıdır.

3. Türkçeyi yabancı dil olarak öğrenenlerin gereksinimlerine, düzeylerine, çeşitliliğine uygun ders öğretim araç, gereçleri ve ders kitapları yeterli değildir. Türkçeyi yabancı dil olarak öğrenenlerin gereksinimlerine ve düzeylerine uygun öğretim programlarının hazırlanması gerekmektedir. Örneğin çocuklar ve yetişkinlerin dil öğrenme biçimleri ve ilgi alanları tamamen farklı olduğundan Türkçeyi yabancı dil olarak öğrenen çocuk ve yetişkinlere uygun ögretim programları ve bu programlara uygun ders kitapları hazırlanmalıdır.

4. Türkçeyi öğrenenlerin çeşitliliğine uygun olarak hazırlanmamış 'tek tip öğretim programı' ve buna koşut oluşturulan ders araç gereçleri ve ders kitapları, öğretim ortamlarını olumsuz yönde etkilemektedir. Türkçenin yabancı dil olarak öğretiminde, çağdaş bir eğitim ortamının oluşabilmesi için yabancı dillerin öğretimine rehberlik etmek üzere hazırlanmış Avrupa Dil Gelişim Dosyasının bu dosyada yer alan ölçütleri kullanmak ve bu dosyaya uygun öğretim materyalleri geliştirmek Türkçe öğretimine büyük ölçüde katk1 sağlayacaktır. 
5. Türkiye de Türkçe öğrenenler, dil okullarında veya kurslardaki sınıflarda, karma gruplarda ders alırlar. Karma gruplara ders veren öğretim elemanları bu tür ortamların gereksinimine hazırlıklı olmadığında sinıf ortamında ve öğretim sürecinde çeșitli sorunlar oluşur. Farklı kültürlere duyarlı, kültürlerin geleneklerin ve faklılıkların farkında olan öğretim elemanlarına gereksinim vardır.

6.Öğrenci açısından ise Türkçe öğrenimi sürecinde Türkçenin sesletimi, biçim bilgisi ve tümce yapısından kaynaklanan çeşitli sorunlarla karşılaşılır.

Dillerin farklı ses yapılarından kaynaklanan sorunları aşmak için derslerde öğrencinin 'kulak dil alışkanlığını' geliştirecek alıştırmalara yer verilmelidir. Öğrenenlerin yaşına ve düzeyine uygun olarak hazırlanan çeşitli etkinlikler, alıştırmalar ve okuma metinleri ile de anlam ve anlatma becerilerinin geliştirilmesi hedeflenmelidir.

7.Öğrencilerin Türkçeyi anlamaya ve anlatmaya ilişkin yaşadığı sorunlar, özenle oluşturulmuş veya seçilmiş yazınsal metinlerin derslerde işlenmesiyle çözümlenebilir. Türkçenin anlam ve anlatım varsıllığını öğrenenlere yansıtmak önemli bir konudur. Türkçe derslerini yavanlıktan kurtarmak için nitelikli metinlerin kullanılması, bu metinlerden hareketle dört temel beceriyi geliştirmeye ilişkin etkinliklerin yapılması, öğrenenlere Türk yazının tanıtılmasıyla Türkçe dersleri, Türk kültürünü ve yaşamını yansıtan kültürlerarası bir köprüye de dönüşecektir.

\section{KAYNAKLAR}

Akerson, F. E (1991) Anlam-Çeviri-Karşılaş̧ırma. İstanbul: ABC Kitabevi. Dam, L. (1995) From Theory to Classroom Practise. Authentik. Dublin.

Karababa Z. C. (1993) Türkçeyle İngilizce Arasında Birbirine Paralel Anlatım Biçimlerinin Değerlendirilmesi. Ankara Üniversitesi (Yayımlanmamış Yüksek Lisans Tezi) Ankara.

Karasar, N. (2009) Bilimsel Araştırma Yöntemi. Ankara: Nobel Yayın.

Little, D. ve R. Perclova. (2000) European Language Portfolio Guide for Teachers and Teacher Trainers. Strasbourg: Modern Languages Division.

Özkan, A. (1994) Yabancı Dil Olarak Türkçe Öğretiminde Ad Durum Eklerinin Öğretilmesiyle İlgili Kimi Görüşler. AÜ TÖMER Dil Dergisi. Ankara

Yıldırım, A. ve H. Şimşek (2006) Sosyal Bilimlerde Nitel Araştırma Yöntemleri. Ankara: Seçkin Yayıncılık. 
